\title{
Relationships among emotional intelligence, ego-resilience, coping efficacy, and academic stress in medical students
}

\author{
Hyo Hyun Yoo ${ }^{1}$ and Kwi Hwa Park ${ }^{2}$
}

${ }^{1}$ Department of Medical Education, Chonbuk National University Medical School, Jeonju, and ${ }^{2}$ Department of
Medical Education, Gachon University College of Medicine, Incheon, Korea

\section{의과대학생의 정서지능, 자아탄력성, 대처효능감과 학업스트레스 간의 관계}

${ }^{1}$ 전북대학교 의학전문대학원 의학교육실, ${ }^{2}$ 가천대학교 의과대학 의학교육학과

\section{유효현 ${ }^{1}$ 박귀화 ${ }^{2}$}

Purpose: The purpose of this study was to identify the causal relationship between emotional intelligence, ego-resilience, coping efficacy, and academic stress.

Methods: Participants were 424 medical students from four medical schools in Korea. We examined their emotional intelligence, ego-resilience, coping efficacy, and academic stress using a t-test, an analysis of variance, correlational analysis, and path analysis. Results: First- and second-year students scored higher on academic stress than did those from third- and fourth-year students. Further, coping efficacy mediated the relationships between emotional intelligence, ego-resilience, and academic stress. Academic stress was directly influenced by coping efficacy, and indirectly by emotional intelligence and ego-resilience. This showed that coping efficacy play an important role in academic stress.

Conclusion: Our findings may help medical schools design educational programs to improve coping efficacy in students, and to reduce their academic stress.

Key Words: Emotional intelligence, Ego-resilience, Coping efficacy, Academic stress

\section{서론}

대부분의 학생들은 많은 스트레스를 경험한다. 일반적으로 적절한 수준의 스트레스는 학생들의 학업수행에 도움을 주지 만 지나친 스트레스는 학업수행 등에 부정적인 영향을 미친 다. 특히 의학을 공부하는 대학생(이하 의과대학생)들은 일반
타 전공 대학생들보다 과도한 학습량과 좋은 성적을 유지하 거나 유급 여부에 대한 심리적 압박감, 여가시간 부족, 대인관 계문제 등으로 인하여 다양한 스트레스를 느끼는데 그 중에 서도 학업과 관련된 스트레스를 가장 많이 겪고 있다[1]. 과도 한 학업스트레스를 지속적으로 겪게 된다면 자신의 능력을 충분히 발휘하지 못하게 되어 결국에는 좋지 못한 학습결과 를 얻게 될 것이다.
Received: April 13, 2015 • Revised: May 6, 2015 • Accepted: May 7, 2015 Corresponding Author: Kwi Hwa Park (http://orcid.org/0000-0002-0008-2400) Department of Medical Education, Gachon University College of Medicine, 38 Dokjeom-ro 3beon-gil, Namdong-gu, Incheon 405-835, Korea

Tel: +82.70.7120.7902 Fax: +82.32.464.5004 email: ghpark@gachon.ac.kr
Korean J Med Educ 2015 Sep; 27(3): 187-193.

http://dx.doi.org/10.3946/kjme.2015.27.3.187

eISSN: 2005-7288

(C) The Korean Society of Medical Education. All rights reserved. This is an open-access article distributed under the terms of the Creative Commons Attribution Non-Commercial License (http:// creativecommons.org/licenses/by-nc/3.0/), which permits unrestricted non-commercial use, distribution, and reproduction in any medium, provided the original work is properly cited. 
그러나 학업스트레스 등과 같은 스트레스는 개인과 환경의 상호작용에 의해 발생되기 때문에 학생 자신이 스트레스를 어떻게 받아들이느냐에 따라 그 결과에 차이가 있다. 피하고 싶은 상황에서 느끼는 불안이나 스트레스 등에 대처하는 개 인의 행동을 예측하게 하는 것이 대처효능감이다[2]. 즉, 대처 효능감은 스트레스 상황에서 충분히 잘 대처할 수 있다는 자 신감을 의미하기 때문에 대처효능감이 높으면 학업 상황에서 인식하는 어려움이나 스트레스에 잘 대처하고 극복하여 학업 을 지속적으로 해 나갈 수 있다[3]. 따라서 학업스트레스에 잘 대처하고 극복하기 위한 대처효능감의 정도와 영향력 등을 파악하는 것은 학업의 불안과 어려움 등으로 발생하는 학업 스트레스를 감소하는 데 도움을 줄 수 있을 것이다.

학업과 관련된 문제는 인지적 요인보다 정의적 요인에 기 인하는 경우가 많다는 연구 결과를 근거로 최근에 사회과학 연구영역에서는 학업스트레스를 조절하는 요인에 대해 관심 이 증대되었다. 이 중 정서지능과 자아탄력성 등 개인적 특성 이 중요한 요인으로 대두되고 있다[4]. 정서지능은 자신과 타 인의 정서를 정확히 인식하고 평가하며 효과적으로 조절하여 자신의 삶을 계획하고 성취하기 위해서 정서를 활용할 수 있 는 능력이다[5]. 정서지능에서 정서와 이성은 분리되어 있지 않고 통합될 수 있는 영역으로 정서는 인지적으로 조절할 수 있고, 반대로 정서가 인지능력을 향상시킬 수 있으며, 인지능 력이 충분히 발휘되도록 간접적으로 돕는다[6]. 정서지능이 높은 사람은 문제해결 및 대처능력이 높고, 학업성취도가 높 으며 학교적응을 잘하는 반면 낮은 불안 수준을 나타낸다[7]. 따라서 정서지능은 정서를 조절하고 활용하여 인지능력을 발 휘할 수 있도록 도와주는 역할을 하여 문제 상황이나 스트레 스에 긍정적 혹은 부정적으로 대처하는 여부를 결정하는 것 에 영향을 미치는 요인이기 때문에 학업스트레스라는 상황을 예측하는 중요한 변인으로 예상된다.

스트레스를 감소시키는 중요한 개인적 특성으로 보고되고 있는 자아탄력성은 좌절되는 스트레스 상황에서 유연하게 반 응하는 경향성으로 개인이 처한 환경적 요구에 대해 자기통 제수준을 조절함으로써 심리적 균형을 유지하고 향상시키도 록 하는 역동적인 능력이다[8]. 자아탄력성이 높은 학생은 인 지적, 사회적으로 융통성 있게 대처하고 학업성취와 학교적 응에서 유의미하게 좋은 결과를 보이며 문제중심적 대처전략
을 사용하는 경향이 있어서 문제 상황이 발생하면 도전하여 스스로 상황을 해결해보려고 노력하는 특성을 보인다[9].

또한 자아탄력성이 높은 학생은 타인에게 적절하게 정서를 조절하여 표현하고, 높은 긍정적 정서를 보였다[10]. 스트레 스 상황에서 자아탄력성이 높은 사람은 효과적인 정서조절기 재를 활용하고[11] 높은 긍정적 정서로 긍정적인 대처전략을 사용하여 좋은 결과를 얻는다[12]. 자아탄력성은 스트레스에 좌절하지 않고 유연하게 대처할 수 있도록 도와주는 요인이 므로 학업스트레스를 예측하는 변인이 될 수 있을 뿐만 아니 라 스트레스 상황에서 정서를 인식하고 조절하고 활용하여 유연하게 대처할 수 있도록 도와주기 때문에 정서지능과 밀 접하게 연관되어 있음을 알 수 있다. 더불어 정서지능과 자아 탄력성은 개인의 정서적 정보를 조절하는 특성이기 때문에 학업스트레스 조절에 영향을 미치는 요인으로 예측된다.

지금까지의 선행 연구들을 종합하면 정서지능, 자아탄력성, 대처효능감과 학업스트레스는 상호관련성은 있다고 예측은 되지만 의과대학생을 대상으로 학업스트레스에 영향을 미치 는 요인으로 이러한 여러 요인들 간의 전체적인 관계와 구조 를 분석한 연구는 드물다. 따라서 본 연구는 의과대학생의 정 서지능, 자아탄력성, 대처효능감과 학업스트레스 정도를 파악 하고 정서지능, 자아탄력성, 대처효능감과 학업스트레스 간의 관계를 규명하며, 이러한 요인들이 학업스트레스에 어떠한 경로로 영향을 미치는지 그 관계를 분석하였다.

\section{대상 및 방법}

\section{1. 연구 대상}

본 연구에서는 4 개의 대학에 재학 중인 의과대학생 129 명 (30.4\%), 의학전문대학원생 295명(69.6\%)으로 총 424명을 대상으로 하였다. 연구 대상의 성별 분포는 남학생 235 명 (58.9\%), 여학생 164명(41.1\%)이었고, 학년별로는 1학년 87 명(20.5\%), 2학년 108명(25.5\%), 3학년 147명(34.7\%), 4학년 82명(19.3\%)이었다. 


\section{2. 연구 방법}

\section{1) 정서지능}

정서지능척도는 Law et al. [13]이 개발한 척도를 사용하였 다. 정서지능척도는 총 16 개 문항이며, 자기감성인식(4문항), 타인감성인식(4문항), 정서조절(4문항), 정서활용(4문항)의 하위 요인으로 구성되었다. 정서지능 중 정서조절과 정서활 용이 학업성취, 학교적응 및 스트레스 등과 관련이 있다는 선 행 연구 결과[14]에 따라 정서조절과 정서활용 하위 변인만을 사용하였고, 본 연구에서의 내적 일치도(Cronbach $\alpha)$ 는 0.82 로 나타났다.

\section{2) 자아탄력성}

자아탄력성척도는 Block \& Kremen [15]이 개발한 척도를 사용하였다. 총 14 개 문항으로 구성되어 있고 점수가 높을수 록 자아탄력성이 높은 것을 의미한다. 본 연구에서의 내적 일 치도(Cronbach $\alpha)$ 는 0.86 으로 나타났다.

\section{3) 대처효능감}

대처효능감을 측정하기 위해서 Klink et al. [16]이 의과대 학생을 대상으로 개발한 척도를 사용하였다. 신뢰도 분석을 통해 14 개 문항 중 문항내적합치도 수준이 낮은 3 개의 문항을 제외한 11 개 문항을 사용하였고, 본 연구에서의 내적 일치도 (Cronbach $\alpha$ )는 0.80 으로 나타났다.

\section{4) 학업스트레스 척도}

학업스트레스를 측정하기 위해서 Kim et al. [17]이 의과대 학생을 대상으로 개발한 스트레스척도를 사용하였다. 학업(9 문항), 임상실습(11문항), 대인관계(7문항), 진로(8문항), 건 강(3문항), 재정(2문항)에서의 스트레스로 총 6개 요인 40문 항으로 구성되었다. 이 중 본 연구에서는 학업스트레스 요인 만을 사용하였고, 내적 일치도(Cronbach $\alpha$ )는 0.82로 나타 났다.

\section{3. 분석 방법}

SPSS version 18.0 (SPSS Inc., Chicago, USA)을 사용하 여 성별, 학제, 학년별 변인들 간의 차이를 분석하기 위해 t-test, one-way analysis of variance를 실시하였고, 각 변 인 간의 관계성을 파악하기 위해 단순상관분석을 시행하였다. 학업스트레스에 직·간접적으로 영향을 주는 변인들 간의 관
계를 살펴보기 위해 변인들 간의 관계를 설정하고, 적합도를 확인하기 위해 AMOS 18.0을 사용하였다. 공분산 구조분석 에서의 계수의 추정 방법으로 최대우도법(maximum likelihood method)을 사용하였으며, 경로모형의 적합도를 판정하 기 위해 절대적합지수로 $\chi^{2} / \mathrm{df}$ 와 root mean square error of approximation (RMSEA)를 사용하였으며, 증분적합지수로 comparative fit index (CFI) 및 Turker-Lewis index (TLI) 를 사용하였다. CFI와 TLI는 0.90 이상이면 적합도가 우수한 것으로, RMSEA는 0.05 이하이면 적합도가 매우 좋은 것으 로, 0.08 이하이면 적합도가 좋은 것으로 판정하였다[18].

\section{결과}

\section{1. 일반적 특성에 따른 변인별 차이}

개인의 일반적 특성에 따른 정서지능, 자아탄력성, 대처효 능감, 학업스트레스의 차이를 분석한 결과(Table 1), 성별과 학제에 따라서는 변인별로 유의미한 차이가 나타나지 않았지 만 $(p>0.05)$ 학년에 따른 학업스트레스는 유의미한 차이가 나 타났다 $(\mathrm{F}=2.87, \mathrm{p}<0.05)$. 즉, 학업스트레스는 2학년이 가장 높고(mean \pm standard deviation, $2.75 \pm 0.43$ ), 3학년이 가장 낮은 것( $2.60 \pm 0.43)$ 으로 나타났다.

\section{2. 변인들 간의 상관관계}

학생들의 정서지능, 자아탄력성, 대처효능감, 학업스트레스 의 평균과 표준편차, 그리고 각 변인간의 상호상관을 분석하 였다(Table 2). 정서지능은 자아탄력성( $\mathrm{r}=0.66, \mathrm{p}<0.01)$ 과 대처효능감 $(r=0.45, p<0.01)$ 과 유의미한 정적 상관이 나타났 지만 학업스트레스(r=-0.07, $\mathrm{p}>0.05)$ 와는 유의미한 상관이 나타나지 않았다. 자아탄력성은 대처효능감 $(r=0.44, p<0.01)$ 과는 유의미한 정적 상관이 있는 것으로 나타났지만 학업스 트레스( $r=-0.07, p>0.05)$ 와는 유의미한 상관이 없는 것으로 나타났다. 대처효능감은 학업스트레스 $(r=-0.33, p<0.01)$ 와 유의미한 부적 상관이 있는 것으로 나타났다. 정서지능과 자 아탄력성은 학업스트레스와 상관이 없고, 대처효능감만이 학 업스트레스와 상관이 있는 것으로 나타났다. 대처효능감이 
Table 1. Differences between Variables by General Characteristics

\begin{tabular}{|c|c|c|c|c|c|c|c|c|}
\hline \multirow{2}{*}{ Factor } & \multicolumn{2}{|c|}{ Emotional intelligence } & \multicolumn{2}{|c|}{ Ego-resilience } & \multicolumn{2}{|c|}{ Coping efficacy } & \multicolumn{2}{|c|}{ Academic stress } \\
\hline & Mean \pm SD & $\mathrm{t} / \mathrm{F} \mid \mathrm{p})$ & Mean \pm SD & $\mathrm{t} / \mathrm{F}(\mathrm{p})$ & Mean \pm SD & $\mathrm{t} / \mathrm{F}(\mathrm{p})$ & Mean \pm SD & $\mathrm{t} / \mathrm{F} \mid \mathrm{p})$ \\
\hline \multicolumn{9}{|l|}{ Gender } \\
\hline Male & $2.80 \pm 0.48$ & 1.99 & $2.75 \pm 0.46$ & -0.66 & $2.80 \pm 0.35$ & -0.88 & $2.68 \pm 0.43$ & 0.50 \\
\hline Female & $2.71 \pm 0.38$ & (0.05) & $2.78 \pm 0.37$ & (0.51) & $2.83 \pm 0.32$ & (0.38) & $2.66 \pm 0.45$ & (0.62) \\
\hline \multicolumn{9}{|l|}{ Group } \\
\hline Medical college & $2.76 \pm 0.45$ & -0.37 & $2.77 \pm 0.47$ & 0.17 & $2.85 \pm 0.35$ & 1.38 & $2.72 \pm 0.44$ & 1.63 \\
\hline Graduate medical school & $2.78 \pm 0.43$ & (0.71) & $2.76 \pm 0.41$ & (0.86) & $2.80 \pm 0.33$ & $(0.17)$ & $2.65 \pm 0.44$ & $(0.10)$ \\
\hline \multicolumn{9}{|l|}{ Grade } \\
\hline 1 st & $2.81 \pm 0.52$ & 0.36 & $2.80 \pm 0.52$ & 0.34 & $2.79 \pm 0.42$ & 0.75 & $2.71 \pm 0.47$ & 2.87 \\
\hline 2nd & $2.75 \pm 0.44$ & (0.79) & $2.76 \pm 045$ & (0.79) & $2.82 \pm 0.38$ & $(0.52)$ & $2.75 \pm 0.43$ & $(0.04)$ \\
\hline $3 r d$ & $2.77 \pm 0.42$ & & $2.74 \pm 0.34$ & & $2.80 \pm 0.27$ & & $2.60 \pm 0.43$ & \\
\hline 4 th & $2.75 \pm 0.39$ & & $2.78 \pm 0.42$ & & $2.86 \pm 0.30$ & & $2.64 \pm 0.41$ & \\
\hline
\end{tabular}

SD: Standard deviation.

Table 2. Means, Standard Deviations, and Correlations between Variables

\begin{tabular}{lcccccc}
\hline \multicolumn{1}{c}{ Factor } & Mean & SD & Emotional intelligence & Ego-resilience & Coping efficacy & Academic stress \\
\hline Emotional intelligence & 2.77 & 0.44 & - & & & \\
Ego-resilience & 2.76 & 0.43 & $0.66^{* *}$ & - & & \\
Coping efficacy & 2.82 & 0.34 & $0.45^{* *}$ & $0.44^{* *}$ & - & \\
Academic stress & 2.67 & 0.44 & -0.07 & -0.07 & $-0.33^{* *}$ & - \\
\hline
\end{tabular}

SD: Standard deviation.

${ }^{*} \mathrm{p}<0.05,{ }^{* *} \mathrm{p}<0.01$.

Fig. 1. The Research Model

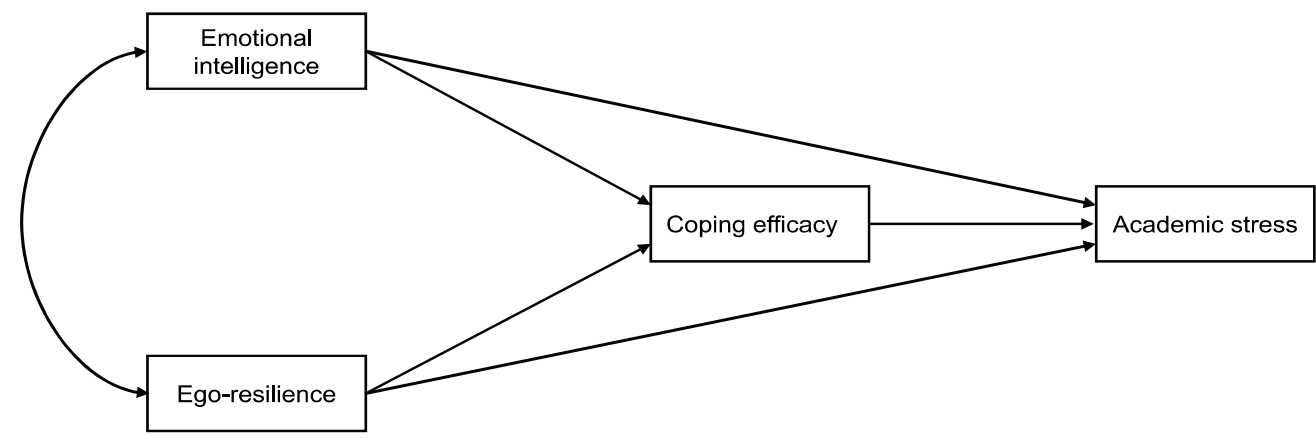

높을수록 학업스트레스가 낮은 것으로 나타났다.

\section{3. 경로모형 검증 결과}

본 연구의 연구모형은 간명모형(parsimonious model)이 아니기 때문에 자유도가 없으며, $\chi^{2}$ 값을 계산하지 않았다. 증 분적합지수인 TLI, CFI는 기준인 0.90을 넘어서 각각 1.00 을 나타냈지만, 절대적합지수 RMSEA는 우수 적합도 수준인
0.08을 넘는 0.30이었다(Fig. 1). 이러한 결과는 연구모형이 전체적으로 매우 적합한 모형이 아님을 의미한다.

대안모형으로 제시된 정서지능, 자아탄력성, 대처효능감, 학업스트레스의 최종 관계 모형의 적합도 지수는 $\chi^{2}=1.66$, $\mathrm{df}=2, \mathrm{p}>0.05, \mathrm{RMSEA}$ 는 0.04, CFI는 0.997, 그리고 TLI는 0.98로 양호하게 나타났다. 정서지능, 자아탄력성, 대처효능 감, 학업스트레스 간의 관계 모형에서 표준화경로계수는 모 
두 $\alpha=0.001$ 수준에서 유의미한 것으로 나타났다(Table 3). 표준화 회귀계수로 경로모형을 구성한 결과, 정서지능은 대 처효능감에 유의미한 긍정적인 영향 $(\beta=0.28)$ 을 주며, 자아 탄력성은 대처효능감에 유의미한 긍정적인 영향 $(\beta=0.26)$ 을 미치는 것으로 나타났다. 한편, 대처효능감은 학업스트레스에 부정적인 영향( $\beta=-0.33)$ 을 미치는 것으로 나타났다(Fig. 2). 이 결과는 정서지능과 자아탄력성이 높을수록 대처효능감도 높아지고, 대처효능감이 높은 학생들은 학업스트레스가 낮음 을 의미한다.

학업스트레스에 영향을 미치는 정서지능, 자아탄력성, 대처 효능감에 대한 직·간접 효과와 총효과를 산출하였다. 학업스 트레스에 영향을 미치는 전체적인 영향력은 총효과이며, 총
효과는 직접효과와 간접효과로 나뉜다. 대처효능감은 학업스 트레스에 미치는 유의미한 직접효과는 -0.33 으로 나타났다. 정서지능과 자아탄력성이 대처효능감을 통하여 학업스트레 스에 영향을 미치는 유의미한 간접효과는 각각 -0.09 와 -0.09 로 나타났다. 그리고 본 경로모형이 학업스트레스의 총 변량 중 약 $11 \%$ 를 설명해 주는 것으로 나타났다(Table 4). 즉, 학 업스트레스는 많은 변인들의 영향을 받는데, 그 변인들 중 정 서지능과 자아탄력성, 대처효능감이 $11 \%$ 영향을 미치는 것으 로 나타났다. 결과적으로 정서지능과 자아탄력성은 대처효능 감을 매개로 하여 학업스트레스에 간접적으로 영향을 미치는 것으로 나타났다.

Table 3. Estimates between Predictor and Outcome Variables

\begin{tabular}{|c|c|c|c|c|c|c|c|}
\hline \multicolumn{3}{|c|}{ Regression weights } & $\begin{array}{c}\text { Unstandardized } \\
\text { estimates }\end{array}$ & $\begin{array}{c}\text { Standardized } \\
\text { estimates }\end{array}$ & SE & CR & p-value \\
\hline Coping efficacy & $\leftarrow$ & Ego-resilience & 0.21 & 0.26 & 0.05 & 4.58 & 0.000 \\
\hline Coping efficacy & $\leftarrow$ & Emotional intelligence & 0.21 & 0.28 & 0.04 & 4.81 & 0.000 \\
\hline Academic stress & $\leftarrow$ & Coping efficacy & -0.42 & -0.33 & 0.06 & -7.03 & 0.000 \\
\hline
\end{tabular}

SE: Standard error, CR: Critical ratio.

Fig. 2. The Path Model of the Effects of the Variables (Alternative Model)

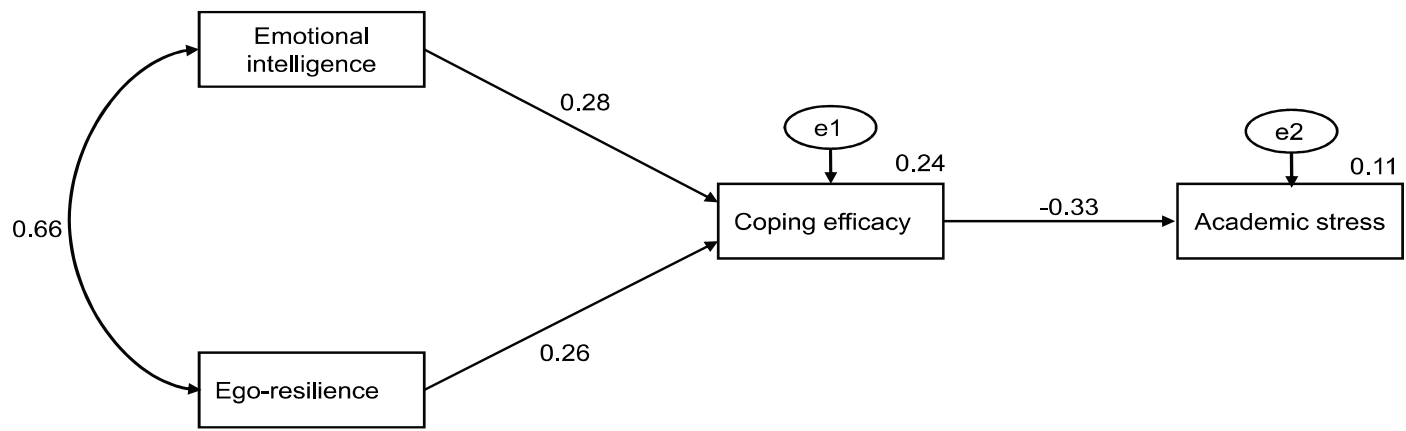

$\chi^{2}(2)=1.66, p>0.05, \chi^{2} / d f=0.83, C F I=0.99, T L I=0.98, R M S E A=0.04$, Method of estimation $=$ maximum likelihood, path values $=$ standardized $\beta$ coefficients.

Table 4. The Direct, Indirect, and Total Effects of Variables on Academic Stress

\begin{tabular}{lcccc}
\hline \multicolumn{1}{c}{ Predicting variable } & Direct effect & Indirect effect & Total effect & SMC $\left(\mathrm{R}^{2}\right)$ \\
\hline Ego-resilience & - & $-0.09^{*}$ & $-0.09^{*}$ & \\
Emotional intelligence & - & $-0.09^{*}$ & $-0.09^{*}$ & 0.11 \\
Coping efficacy & $-0.33^{*}$ & - & $-0.33^{*}$ & \\
\hline
\end{tabular}

SMC: Square multiple correlation. ${ }^{*} p<0.001$. 


\section{고찰}

본 연구의 목적은 의과대학생들의 정서지능, 자아탄력성, 대처효능감이 학업스트레스와 어떠한 관계가 있고, 정서지능, 자아탄력성, 대처효능감이 어떠한 경로로 학업스트레스에 영 향을 미치는지를 분석하는 것이다. 분석 결과를 요약하고 논 의하면 다음과 같다.

성별, 학제, 학년별로 정서지능, 자아탄력성, 대처효능감, 학업스트레스의 차이를 분석한 결과 성별, 학제별로는 변인 들의 차이가 나타나지 않았다. 남학생이나 여학생, 또는 의학 전문대학원생이나 의과대학생 모두 유사한 수준의 정서지능, 자아탄력성, 대처효능감, 학업스트레스를 가지고 있음을 알 수 있다. 그러나 학년별로는 학업스트레스를 고학년보다는 저학년이 더 많이 느끼는 것으로 나타났다. 의과대학의 1,2 학년은 기초의학과 임상의학이라는 의학전반에 대한 지식 중 심의 과중한 학습량 때문에 학업스트레스가 3,4 학년보다 높 게 나타난 것으로 사료된다. 하지만 3,4 학년의 경우에도 임 상실습 교육과정이라는 의료현장에서 느끼는 스트레스가 높 을 것이다. 이는 의과대학은 학년별로 직면하는 교육과정, 교 육환경 등이 연속적으로 변화하기 때문에 스트레스의 원인과 정도 등에 차이가 있다는 점을 고려하여 상담이나 지도, 멘토 링 등이 이루어져야 함을 시사한다.

정서지능과 자아탄력성은 대처효능감이라는 매개변인을 통하여 학업스트레스에 간접적으로 영향을 미치고, 대처효능 감은 학업스트레스에 직접적으로 영향을 미치는 것으로 나타 났다. 이는 정서지능과 자아탄력성은 상호관련성이 있고[11], 정서지능과 자아탄력성이 높은 학생들은 스트레스 상황을 긍 정적으로 대처해나갈 수 있다는 선행 연구[12,14]와 일치한 다. 또한 대처효능감은 학업스트레스에 직접적으로 영향을 미치기도 하지만, 정서지능과 자아탄력성을 매개하는 중요한 변인임을 알 수 있다. 대처효능감은 학업적응에 가장 중요한 요소라는 선행 연구 결과[19]도 본 연구 결과를 부분적으로 지지해준다. 개인의 내재적인 특성인 정서지능과 자아탄력성 이 학업스트레스에 영향을 미치는 요인이지만 직접적으로 영 향을 미치기 보다는 특성들을 주어진 상황에 맞추어 인식하 고 판단하는 자기조절의 과정인 대처효능감을 통할 때 학업
스트레스에 영향을 미치는 것으로 판단된다. 따라서 학업스 트레스를 조절하여 긍정적인 학습성과 달성을 도와주기 위해 서 스트레스 대처와 관련된 내용을 교육과정 안에 일부 수업 으로 편성하거나 대처효능감을 높여주는 교육프로그램을 개 발하여 지속적으로 제공해 주는 노력이 필요하다.

의과대학생들의 학업달성 정도는 인간의 생명과 건강 등의 문제를 해결하기 위해서 필요한 기본적인 학습내용을 어느 정도 숙달했는지를 의미하는 하나의 척도로 졸업 후 의사로 서의 자질과 능력을 결정하고, 더 넓게는 우리나라 의료의 질 적 수준에 영향을 미칠 수 있는 문제이기 때문에 학생 개인은 물론 사회적으로 관심을 가져야 할 것이다. 그러나 학생들과 가장 가까이에 있는 의과대학의 교수들은 학생들의 심리적 요구에 둔감하고 학업에 영향을 줄만한 정서적, 심리적 문제 를 가지고 있는 학생들을 감지하는 수준이 낮은 것으로 보고 되었다[20]. 따라서 본 연구는 교수 및 학교관계자들에게는 학생들의 학업스트레스에 영향을 미치는 정서지능, 자아탄력 성, 대처효능감과 같은 개인의 정서적 특성의 중요성을 인식 하고 지도할 수 있는 가이드를 제공해주는 데 의의가 있다. 학 업스트레스를 감소시키거나 조절할 수 있는 역량을 강화할 수 있도록 지도해 줌으로써 많은 의과대학생들이 학습성과를 달성하여 향후 유능한 의료인으로 성장할 수 있도록 도와주 기 위한 기본적인 정보를 제공함에 의의가 있다. 또한 학생에 게는 자기 스스로 학업스트레스의 원인을 생각해보고 조절할 수 있는 자아성찰역량을 갖추는 것의 중요성과 필요성을 인 식하게 하는 데 기여할 것을 기대한다. 학업스트레스 감소를 위한 다양한 교육프로그램을 개발할 때 반드시 고려해야 하 는 요인들에 대한 기초 정보를 제공해줄 수 있다는 점에서도 의의가 있다.

그러나 본 연구는 일부 지역의 의학전문대학원과 의과대학 만을 대상으로 표집하였기 때문에 연구 결과를 일반화하기 어렵고, 스트레스척도 중 일부 하위 척도만을 사용한 점에 한 계가 있다. 또한 개인적 특성들을 총체적으로 고려하지 않고 학업스트레스와 관련된 변인들을 일부 한정하여 살펴보았기 때문에 향후 학업스트레스에 영향을 미치는 다양한 변인과 학업스트레스를 감소시키기 위한 구체적인 방안이나 교육프 로그램의 효과분석 등과 같은 보다 심층적인 추후 연구가 필 요하다. 
Acknowledgements: None.

Funding: None.

Conflicts of interest: None.

\section{REFERENCES}

1. Vitaliano PP, Russo J, Carr JE, Heerwagen JH. Medical school pressures and their relationship to anxiety. J Nerv Ment Dis 1984; 172: 730-736.

2. Hackett G, Byars AM. Social cognitive theory and the career development of African American women. Career Dev Q 1996; 44: 322-340.

3. Zajacova A, Lynch SM, Espenshade TJ. Self-efficacy, stress, and academic success in college. Res High Educ 2005; 46: 677-706.

4. Kim KS, Kim YK, Park YM, Seo KS. Effect of camping participation on resilience and academic stress among the juvenile. J Korea Contents Assoc 2014; 14: 1010-1020.

5. Salovey P, Mayer JD. Emotional intelligence. Imagin Cogn Pers 1990; 9: 185-211.

6. Mayer JD, Caruso DR, Salovey P. Emotional intelligence meets traditional standards for an intelligence. Intelligence 1999; 27: 267-298.

7. Bastian VA, Burns NR, Nettelbeck T. Emotional intelligence predicts life skills, but not as well as personality and cognitive abilities. Pers Individ Dif 2005; 39: 1135-1145.

8. Block J, Block JH. Venturing a 30-year longitudinal study. Am Psychol 2006; 61: 315-327.

9. Dumont M, Provost MA. Resilience in adolescents: protective role of social support, coping strategies, selfesteem, and social activities on experience of stress and depression. J Youth Adolesc 1999; 28: 343-363.
10. Klohnen EC. Conceptual analysis and measurement of the construct of ego-resiliency. J Pers Soc Psychol 1996; 70: 1067-1079.

11. Tugade MM, Fredrickson BL. Resilient individuals use positive emotions to bounce back from negative emotional experiences. J Pers Soc Psychol 2004; 86: 320-333.

12. Folkman S, Moskowitz JT. Positive affect and the other side of coping. Am Psychol 2000; 55: 647-654.

13. Law KS, Wong CS, Song LJ. The construct and criterion validity of emotional intelligence and its potential utility for management studies. J Appl Psychol 2004; 89: 483-496.

14. Choi J. Effects of emotional intelligence and ego-resilience on adjustment to college life [master's thesis]. [Seoul, Korea]: Yonsei University; 2008.

15. Block J, Kremen AM. IQ and ego-resiliency: conceptual and empirical connections and separateness. J Pers Soc Psychol 1996; 70: 349-361.

16. Klink JL, Byars-Winston A, Bakken LL. Coping efficacy and perceived family support: potential factors for reducing stress in premedical students. Med Educ 2008; 42: $572-579$.

17. Kim MJ, Park KH, Yoo HH, Park IeB, Yim J. Development and validation of the medical student stress scale in Korea. Korean J Med Educ 2014; 26: 197-208.

18. Byrne BM. Structural equation modeling with AMOS: basic concept, applications, and programming. Mahwah, USA: Lawrence Erlbaum Associates; 2001.

19. Yune SJ, Park KH, Chung WJ, Lee SY. The effects of attribution tendencies, academic stress, and coping efficacy on academic adjustment of medical students. Korean J Med Educ 2011; 23: 167-174.

20. Alexander DA, Haldane JD. Medical education: a student perspective. Med Educ 1979; 13: 336-341. 